\section{The correlation of consuming thymoquinone extract of nigella sativa to tooth socket re-epithelization on diabetic induced rats}

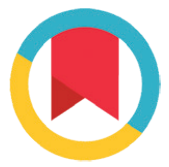

CrossMark

\author{
Mei Syafriadi, ${ }^{,}$Putri R. Yusuf, Sabrina M. Pratama, Dina Z. Ummah, Khoirul Amalia
}

\title{
Abstract
}

Objective: The purpose of this research is to determine the effect of Tq to re-epithelialization at the margin of tooth socket post extraction in diabetic rats.

Material and Methods: Used 27 rats were induced diabetic with streptozotocin (STZ) dose of $50 \mathrm{mg} / \mathrm{kg}$ body weight of rats which divided into 3 groups that has been stained with hematoxillin-eosin and cytokeratin 19. They are P1 treated with thymoquinone (Tq), P2 treated with metformin, and $\mathrm{K}$ without treatment. Each group consist of 9 rats were divided into 3 subgroups based on day of observation.
They are 3rd, 7th and 10th day post-extraction. Re-epithelialization was observed at the margin of the tooth socket that has been stained with hematoxillin-eosin and cytokeratin 19

Results: showed there was an improvement of re epithelialization percentage in the Tq treatment group compared with $\mathrm{P} 2$ and $\mathrm{K}$ groups.

Conclusion: Thymoquinone extract may decrease blood glucose level and increasing re-epithelialization in margin of the tooth socket after extraction in diabetic rats.
Department of Biomedical Science, Laboratorium of Oral Pathology, Faculty of Dentistry, Jember University, Jember, Indonesia

*Corresponding to: Mei Syafriadi, Department of Biomedical Science, Laboratorium of Oral Pathology, Faculty of Dentistry, Jember University, Jember, Indonesia didiriadihsb@gmail.com

Received: 4 June 2018 Revised: 4 June 2018 Accepted: 9 July 2018 Available Online 1 August 2018

Keywords: Tooth extraction, Diabetic, Re-epithelialization, Thymoquinone

Cite this Article: Syafriadi M, Yusuf PR, Pratama SM, Ummah DZ, Amalia K. 2018. The correlation of consuming thymoquinone extract of nigella sativa to tooth socket re-epithelization on diabetic induced rats. Journal of Dentomaxillofacial Science 3(2): 79-83. D0I: 10.15562/jdmfs.v3i2.742

\section{Introduction}

Diabetes Mellitus (DM) is a disorder metabolism that can be characterized by hiperglycemia. ${ }^{1,2}$ Prevalence of DM in indonesia increase every year, from 382 million in 2013 became 592 million in 2015 and the number of incident in woman is higher than the man. ${ }^{3}$

Hiperglycemia occur because there is a destruction in pancreatic cells or dysfunction of insulin or both of them. ${ }^{4}$ Hiperglycemia in the long term will lead glycation process to lipid and protein that have resulted AGEs increasing (Advanced Glycation End-products) and then AGEs products in the blood circulation interact with RAGEs (Receptor of Advanced Glycation End-products). ${ }^{5}$ Increasing number of AGEs and RAGEs interactions in circulation causes dysfunction of neutrophil, decreasing ability of transendhotelial migration, suppressing activity of phagocytic cells and decreasing the number of neutrophil infiltration. Those of them causes microvascular and macrovascular disorders. ${ }^{6-8}$

$\mathrm{DM}$ in long term make wound healing disorder. It should take attention for surgery treatment such as tooth extraction that can effect to prolong of healing time and make dry socket or alveolar osteitis. ${ }^{9,10}$
The preventing for that cases are minimalizing of post extraction complications through controlling of blood glucose concentration. Metformin is a synthesis drug that is often used for DM therapy but it has side effects like lactic acidosis until causing death. ${ }^{11-13}$ WHO suggest to consume herbal medicine for DM therapy. Thymoquinone (Tq) extracts of black cumin have an anti DM that commonly used. Thymoquinone extracts considered have an effect to increase tooth socket re-epithelization process in diabetic induced rats. ${ }^{14,15}$

Based on literature above, $\mathrm{Tq}$ extract considers can decrease blood glucose level by repairing of $\beta$-cell pancreas, and protect AGEs formation in the beginning until at the end. ${ }^{12}$ We also consider that Tq extract can decrease matrix metalloproteinase (MMPs) such as MMP-2 and MMP-9. The decrease of MMPs will increase re-epitelization process. ${ }^{13}$

We conducted an experimental study that aims to determine the effect of $\mathrm{Tq}$ extract from black cumin toward re-epithelization of marginal socket post extraction in diabetic induced rats. We hope this research can contribute to increase herb medicine field and development of using herb medicine in dentistry. 


\section{Material and Methods}

The research was conducted after the approval of the ethics committee. The research used laboratory experimental with post control only group design which used total amount 27 rats who adapted along 1 week.

All samples had been fasted for 8 hours, before induced by streptozotocin (STZ) $50 \mathrm{mg} / \mathrm{kg}$ body weight (BW) in $0.1 \mathrm{M}$ citrate acid buffer $\mathrm{pH}$ 4.5. Soon as possible after injected, all the samples have given glucose solution to protect from hypoglicaemic syock. After all samples injected by STZ, diabetic rat categorize if they have blood glucose level $\geq 250 \mathrm{mg} / \mathrm{dL}$, then diabetic rat samples devided into 3 groups (P1, P2 and K group), each groups contain 9 rats which for $\mathrm{P} 1$ group was treated with Tq extract $80 \mathrm{mg} / \mathrm{kg}$ BW that solved in olive oil, then for P2 group as positive control was treated with metformin $100 \mathrm{mg} / \mathrm{kg}$ BW that solved with aquadest and $\mathrm{K}$ Group as negative control was treated with aquadest. P2 dan $\mathrm{K}$ group treated three times a day, while P1 group once time a day by intra gastric tube for seven days. Then under anesthetized by ketamin $0.15 \mathrm{ml} / 100 \mathrm{gr} \mathrm{BW}$ tooth extracted on left mandible first molar were done for all samples, using excavator and clamp. Tooth socket extended with diamond bur round end no. 1 using micromotor contra angle handpiece low speed with 5000 speed rpm for 2 second. All samples continuously treated with $\mathrm{Tq}$, metformin and aquadest after extraction.

Three samples in each treated group decaputated at 3rd, 7th and 10th day after extraction. Left mandible was taken from insisive until posterior teeth, after that samples soaked in fixation solution used formaldehyde buffer $10 \%$ for 24 hour.

Decalsification was done by formic acid $10 \%$ for 7th days. Tissue slide performed through Paraffinembedded tissue block cutting using microtom $6 \mu \mathrm{m}$ in thickness. Two slides made from each samples. The first slide stainned by Hematoxyline Eosin (HE) and second slide stainned by

Blood Glucose Level (BGL)

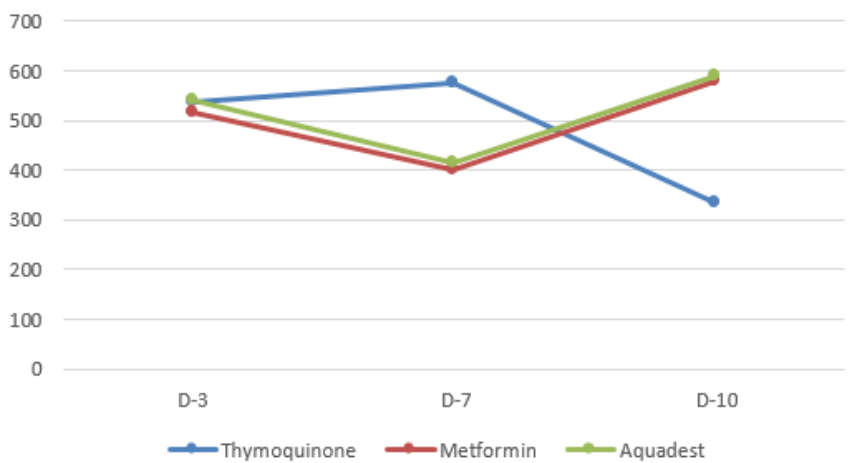

Figure 1 The graph of blood glucose levels (BGL) on 3rd day (D-3), 7th day (D-7) and 10th day (D-10)
Immunohistochemistry (IHC) with Citokeratin-19 (CK-19).

All slides were observed by light microscope with 40x and 100x magnification. Measurement of re-epithelization length was done using CK-19 expression slide with the method as follow. ${ }^{16}$

$\mathrm{R}=\frac{1 \mathrm{EET}}{1 \text { Wound }}$

$\mathrm{R}$

1 EET : Lenght of EET (Epidermal Epithelial Tongue)

1 Wound : Lenght of wound gap

(Note: 1 EET measured from epithelial tooth socket edges to the end of new epithelization. 1 wound measured from epithelial tooth socket edges to mesio servical of second molars)

The Data will be ratio value and analyze using kolmogorov smirnov to know whereas the data is normal distribution and homogeneity determine using Levene test. If the data normal distribution and homogen, the test is performed by one way annova with $\mathrm{p}<0.05$. If the data is not normal distribution and not homogen, Kruskal-wallis test will used. Then all data continued to correlation regression test.

\section{Results}

Figure 1 shows Blood Glucose Level (BGL) in each group on $3 \mathrm{rd}, 7$ th and 10 th day. The averages of BGL of Group P2 (as positive control) and group $\mathrm{K}$ (negative control) decreased from 3rd to 7 th day, but they increased in 10 th day $(538 \mathrm{mg} /$ $\mathrm{dL}$ and $575 \mathrm{mg} / \mathrm{dL}$ respectively). It was different with $\mathrm{P} 1$ group ( $\mathrm{Tq}$ treatment) whereas $\mathrm{BGL}$ is little bit increased from 3 rd to 7 th day, but it was decrease clearly in 10 th day $(334.3 \mathrm{mg} / \mathrm{dL})$. Nevertheless all samples are still hyperglycemic as long as investigation.

Based on histopathological appearance of each group with $\mathrm{HE}$ and CK-19 stainning. re-epithelization on the tooth socket margin begin from mesial side grow and moved toward apical irregularly in a granulation tissue along mesial wall of tooth socket. Re-epithelization in 3rd day on $\mathrm{K}$ group was seen clearly than P1 and P2 figure 2.

Re-epithelization of $\mathrm{K}$ group became worse in 7 th day and 10th day but it seen better progress in $\mathrm{P} 1$ group than $\mathrm{K}$ and $\mathrm{P} 2$ group figure 3 and figure 4.

The Measurement of re-epithelization length of tooth socket in each group showed any variations, but P1 group showed re-epithelization length is better than P2 and $\mathrm{K}$ groups. The re-epithelization in 


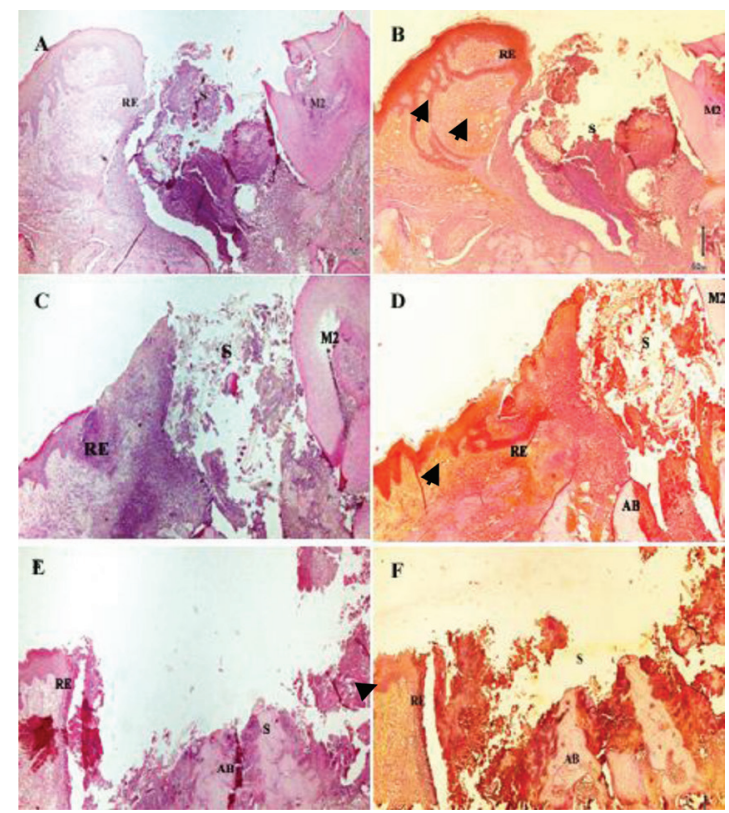

Figure 2 Histopathological appearance on 3rd day post extraction (HE staining: A, C, $\mathrm{E}$ and CK-19 stainning: B, D, F). Reepthelization begin from mesial tooth socket toward apical in granulation tissue along mesial tooth socket (head arrow) (K group: A-B; P1 group: C-D; $\mathrm{P} 2$ group: E-F. RE is re-epithelization tongue; $\mathrm{AB}=$ alveolar bone; $\mathrm{S}$ is tooth socket; M2 is 2nd molar. Magnification 40x)

P1 group was reached $74.65 \%$ in length while $38.56 \%$ and $25.93 \%$ in length on $\mathrm{P} 2$ and $\mathrm{K}$ groups on 10th day post extraction figure 5 but statistically not significant $(p>0.05)$ between each group.

Based on linear correlation regression test between BGL and average percentage of re-epithelization showed weak correlation for P1 group with $\mathrm{R}$ square value was $=0.277$ (weak), meanwhile P2 and $\mathrm{K}$ groups were very weak $(\mathrm{R}=0.002$ and 0.001$)$.

Based on the results above, it was any different re-epithelization level among each group. In P1 group, the re-epithelization lenght showed a progress on 3rd day to 7 th day and 7 th day to 10th day. They are $56.61 \%, 53.05 \%$ and $74.65 \%$ respectively, also in $\mathrm{P} 2$ group, there was re-epithelization progress but it is until 7 th day only $(52.59 \%)$ then decreased on 10th day that have average $38.56 \%$, meanwhile in $\mathrm{K}$ group showed re-epithelization length was good enough in 3rd day (48.30\%), after that re-epithelization was decrease until 10th day which is the re-epi-thelization lenght only reached $25.93 \%$.

The differences of re-epithelizations lenght was influenced by the differences of treatment. The increasing of the re-epithelization lenght in P1 group

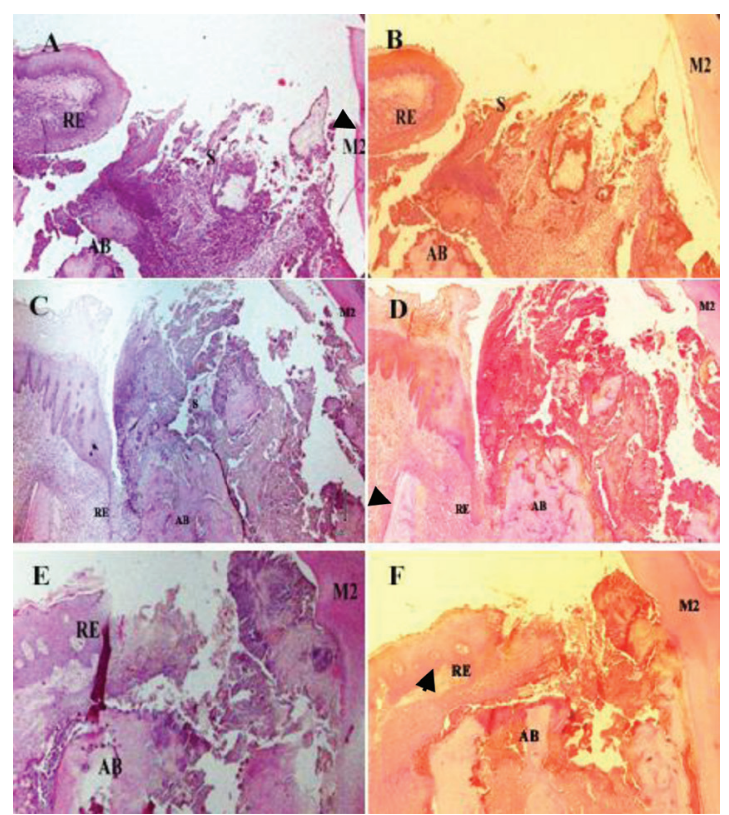

Figure 3 Histopathological appearance on 7th day post extraction (HE staining: A, C, E and CK-19 stainning: B, D, F). Elongation of Re-epithelization from mesial tooth socket toward apically (head arrow) seem clearly over alveolar bone in P1 group than $\mathrm{K}$ dan $\mathrm{P} 2$ group (K group: A-B; P1 group: C-D; P2 group: E-F. RE is re-epithelization tongue; $\mathrm{AB}$ is alveolar bone; $\mathrm{S}$ is tooth socket; M2 is 2nd molar. Magnification 40x)

on 10th day was associated with decreasing of BGL after treated with Tq extract.

The given of $\mathrm{Tq} 80 \mathrm{mg} / \mathrm{kg} \mathrm{BW}$ in rat could decrease BGL after 45 days consuming. ${ }^{17}$ While in P2 group and $\mathrm{K}$ group, re-epithelization length is not good enough perhaps BGL is still high above of normal level. The decrease of BGL will accelerate the process of re-epithelization on the margin of tooth socket post extraction.

\section{Discussion}

Consuming tymoquinone extract in P1 samples showed that have effect to decreases BGL figure 1. Decreasing of BGL made inflammatory cells migrate to tooth socket area easily to performed granulation tissue. Which it is needed to stimulate and accelerate socket re-epithelization. ${ }^{17,18}$

Decreasing BGL through any pathway; one of them is decreasing oxidative stress. A decrease of oxidative stress by $\mathrm{Tq}$ could protect pancreatic islet $\beta$-cells from damage and also can stimulate pancreatic $\beta$-cell regeneration therefore insulin can produce adequately. ${ }^{19}$

The other way decreases BGL by Tq is suppressing 

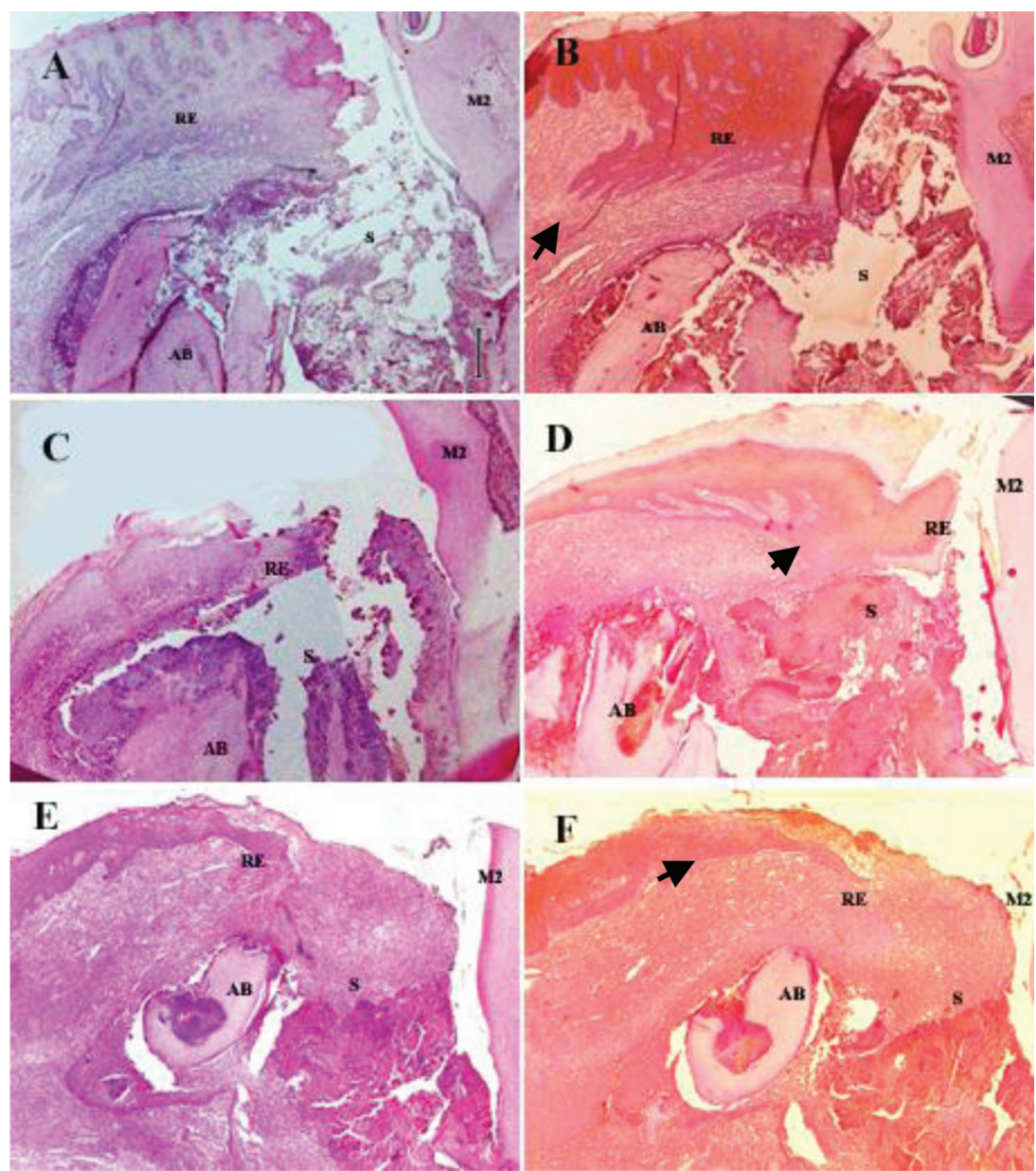

Figure 4 Histopathological appearance on Day-10 post tooth extraction (HE staining: A, C, E and CK-19 stainning: B, D, F). Elongation of re-epithelization from mesial tooth socket toward mesio-cervical M2 seem clearly over fibroblast tissue in P1 and P2 group (arrow head). Eventhough $\mathrm{K}$ group seem similar but the epithelial proliferation seem irregularly down forward of socket. (K group: A-B; P1 group: C-D; P2 group: E-F. RE is re-epithelization tongue; $\mathrm{AB}$ is alveolar bone; $\mathrm{S}$ is tooth socket; $\mathrm{M} 2$ is 2 nd molar. Magnification $40 \mathrm{x})$

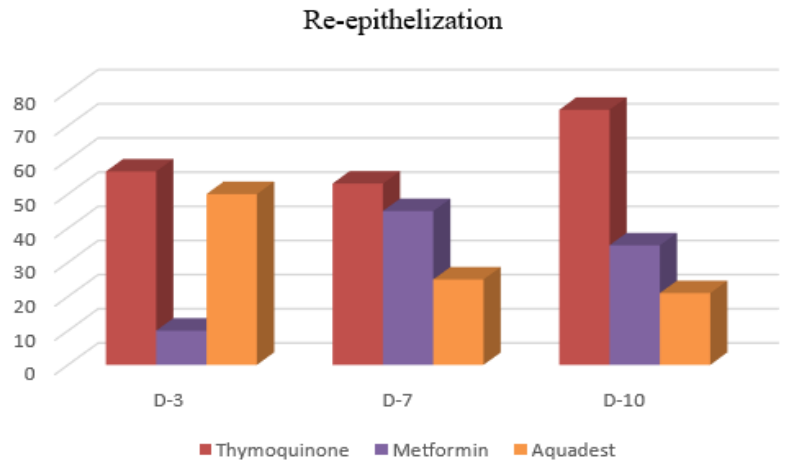

Figure 5 The diagram average percentage (\%) of re-epithelization above of tooth socket on 3rd day (D-3), 7th day (D-7) and 10th day (D-10)

of gluconeogenic enzyme which plays an important role in the process of gluconeogenesis such as phospoenol pyruvatecarboxykinase (PEPCK), glucose 6 phospate, fructose 1.6 bisphospatase. This enzyme in diabetic patient had been increasing because of insulin dysfunction then lead hyperglicaemia. ${ }^{5,17}$

The group that treated by metformin (P2), there was no visible a significant decreasing of BGL and tend fluctuate, even, increased on 10th day. That metformin with doses of $100 \mathrm{mg} / \mathrm{kg}$ BW for 3times/day could decrease BGL in diabetic rats. The mechanism after consuming metformin will decrease mRNA that codes PEPCK enzyme, which has plays in initiate of gluconeogenesis by catalyzed decarboxylation and phosphorylation reaction to change oxaloacetate into Phosphoenolpyruvate. ${ }^{20}$

In this research, there is no effect of consuming metformin (P2 group) maybe caused by cross reaction of metformin with food in rat stomach. Rat feeding in this research was ad libitum. if consuming metformin while the stomach was full it could be inhibit drug absorption to reach Concentration maximum (Cmax) in blood. The present of food in stomach will decrease absorption process of metformin then reduces $40 \%$ of Cmax in blood. ${ }^{21}$

The correlation between BGL and re-epithelization in this animal study are not show linearity (the linearity week and very weak), it was appropriate with the theory that state before. ${ }^{9,10}$

Theoretically, the elongation of re-epithelization in diabetic patient will increase if BGL decrease. The slowly of wound healing can be related to the high value of BGL that can trigger increasing the forming Reactive Oxygen Species (ROS) which will improve the signaling NADPH Oxidase. This circumstance causes the phosphorylation and degradation of inhibitor of NF-k $\beta$ that is $\operatorname{Ik} \beta$. Phosphorylation and degradation of $\operatorname{Ik} \beta$ can causes release NF-k $\beta$ and than NF-k $\beta$ translocate into the nucleus cell, so that occurs an increasing of expression regulation of pro-inflammatory cytokines such as TNF- $\alpha$ and IL- $1 \beta$. The present of TNF- $\alpha$ regulation causes decreasing regulation of TGF- $\beta 1$ which is useful to increase the proliferation of keratinocytes cell (epithelial cells) on the injured area and at the same time decrease apoptosis cells of re-epithelization. ${ }^{22,23}$

\section{Conclusion}

Based on the histopathological appearance and re-epithelization measurement, it seems that the healing tooth socket of P1 group is better than $\mathrm{P} 2$ and $\mathrm{K}$ groups. The healing of the socket in $\mathrm{K}$ group was seen irregular retepeg and it could not migrate perfectly to close the tooth socket. Maybe the re-epithelization obstacle in K group occurred 
because of dry socket, so it did not have enough connective tissue and bones supporting inside of tooth socket.

In this research all tooth socket group still not closure completely, because the BGL still high above normal, but the group which treated with Tq extract (P1) tend have better tooth socket re-epithelization than $\mathrm{P} 2$ and $\mathrm{K}$ group. Further research is needed Tq research for longer periods until BGL normally and re-epithelization process is completely.

\section{Acknowledgment}

The writer said thank you to Indonesian Government especially for Ministry of research, technology, and higher education that's support funded this research in year 2016-2017.

\section{Conflict of Interest}

The authors report no conflict of interest in this research.

\section{References}

1. Wijaya R, Wu L. Inhibition of a-glukosidase and amylase activities of some Indonesian Herbs: In Vitro Study. The 12th ASEAN food Conference. 2011

2. Guyton AC, Hall JE. Buku Ajar Fisiologi Kedokteran. 11th ed. Jakarta: EGC; 2006.

3. Kementerian Kesehatan. Riset Kesehatan Dasar. 2013.

4. Sudoyo AW, Setiyohadi B, Alwi I, et al. Buku Ajar Ilmu Penyakit Dalam. Jakarta: Internal Publishing; 2009.

5. Al-Farabi MJ. Antibodi terhadap advanced glycation end product, cara mutakhir pencegahan komplikasi diabetes mellitus. CDK 2013;40: 807-814.

6. Collison KS, Parhar RS, Saleh SS, et al. RAGE- ediated neutrophil dysfunction is evoked by advanced glycation end products (AGEs). J Leukoc Biol 2002;71: 433-444.

7. Abiko Y, Selimovic D. The mechanism of protracted wound healing on oral mucose in diabetes. Review Bosn J Basic Med Sci 2010;10: 186-191.

8. Radoi V, Lixandru D, Mohora M, et al. Advanced glycation end products in diabetes mellitus: mechanism of action and focused treatment. Proc Rom Acad Series B 2012;1: 9-19.
9. Huang S, Dang H, Huynh W, et al. The healing of dental extraction sockets in patients with type 2 diabetes on oral hypoglycaemics: a prospective cohort. Aust Dent J 2013;58: 89-93.

10. Torres-Lagares D, Srrera-Figallo MA, RomeroRu'iz MM, et al. Update on dry socket: a review of the literature. Med Oral Patol Oral Cir Bucal 2005;10: 77-85.

11. Vernillo AT. Dental consideration for the treatment of patients with diabetes mellitus. Am Dent Asscoc 2003;134: 24-33.

12. Davidson J, Howlett H. New prolonged-release metformin improves gastrointestinal tolerability. Br J Diabetes Vasc Dis 2004;4: 273-277.

13. Aksay E, Yanturali S, Bayram B, et al. A rare side effect of metformin: metformin induced hepatoxicity. Turk J Med Sci 2007;37: 173-175.

14. Kaleem M, Kirmani D, Asif M, et al. Biochemical effect of nigella sativa 1 seeds in diabetic rats. Indian J Exp Biol 2006; 44: 745-748.

15. Paarakh PM. Nigella sativa linn. a comprehensive review. Indian J Nat Prod Resour 2010;1: 409-429.

16. Safferling K, Sutterlin $\mathrm{T}$, Westpal $\mathrm{K}$, et al. Wound healing revised: a novel re-epithelialization mechanism revealed by in vitro and in silico models. J Biophys Biochem Cytol 2013;203: 691-709.

17. Pari, Sankaranarayanan C. Beneficial effects of thymoquinone on hepatic key enzymes in streptozotocinnicotinamide induced diabetic rats. Life Sciences 2009;85: 830-834.

18. Ramirez H, Patel SB, Pastar I. The role of TGF- $\beta$ signaling in wound epithelization. WOUND CARE 2014;3: 482-491.

19. Abdelmeguid NE, Fakhoury R, Kamal SM, et al. Original article: effects of nigella sativa and thymoquinone on biochemical and subcellular changes in pancreatic BCells of streptozotocin induced diabetic rats. J Diabetes 2010;2: 256-266.

20. Yuan L, Ziegler R, Hamann A. Inhibition of phosphoenol pyruvate carboxykinase gene experession by metformin in cultured hepatocytes. Chin Med J 2002;115: 1843-1848.

21. Graham GG, Punt J, Arora M, et al. Clinical pharmacokinetics of metformin. Clin Pharmacokinet 2011;50: 81-98.

22. Gloire G, Legrand-Poels S, Piette J. NF-kB activation by reactive oxygen species: fifteen years later. Biochem Pharmacol 2006;72: 1493-1505.

23. Koivisto L, Häkkinen L, Larjava H. Reepithelization of wound healing: cell biology and clinical management 1st ed. John Wiley \& Sons Inc. 2012.

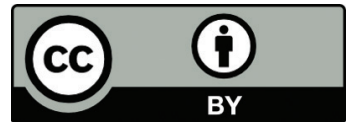

This work is licensed under a Creative Commons Attribution 